\title{
A relação da afetividade professor/aluno no processo de ensino-aprendizagem
}

\author{
The relationship between teacher/student affectivity in the teaching- \\ learning process
}

\author{
Laura Helena Osório Veloso (lauraveloso48@ gmail.com) \\ Universidade Federal do Pampa (UNIPAMPA)
}

Renata Godinho Soares (renatasoares1807@gmail.com) Universidade Federal do Pampa (UNIPAMPA)

Jaqueline Copetti (jaquelinecopetti@unipampa.edu.br)

Universidade Federal do Pampa (UNIPAMPA), Grupo de Estudos e Pesquisa em Estágio e Formação de Professores - GEPEF

Resumo: A relação interpessoal e a afetividade são fatores fundamentais para o crescimento e desenvolvimento do ser humano. Com o objetivo de verificar a compreensão de professores e alunos sobre a afetividade e a relação desta com o processo de ensino-aprendizagem, efetuou-se um estudo de natureza qualitativa. Participaram do estudo professores e alunos do $9^{\circ}$ ano do ensino fundamental de uma escola pública do município de Uruguaiana/RS. Para coleta de dados com os professores foi utilizado um questionário com questões sobre o perfil, bem como perguntas ligadas à afetividade no processo de ensino-aprendizagem. Quanto aos alunos, foi utilizado um questionário e realizado um grupo focal com as duas turmas do $9^{\circ}$ ano do ensino fundamental participantes do estudo. Como resultados pode-se observar que na relação professor/aluno, a afetividade é de suma importância em sala de aula onde o professor torna-se mediador entre essa interação de razão e emoção. Percebeu-se que uma relação de maior afetividade e diálogo entre professor/aluno acaba por tornar a aprendizagem mais significativa.

Palavras-chave: Afeto; Ensino-aprendizagem; Relacionamento-interpessoal.

\begin{abstract}
The interpersonal relationship and affection are fundamental factors for the growth and development of the human being. In order to verify the understanding of teachers and students about affectivity and its relationship with the teaching-learning process, a qualitative study was carried out. Teachers and students of the 9th grade of elementary school of a public school in the municipality of Uruguaiana/RS participated in the study. For data collection with teachers, a questionnaire was used with questions about the profile, as well as questions related to affectivity in the teaching-learning process. As for students, a questionnaire was used and a focus group was held with the two classes of the 9th grade of elementary school participating in the study. As a result, it can be observed that in the teacher/student relationship, affectivity is of paramount importance in the classroom where the teacher becomes a mediator between this interaction of reason and emotion. It was noticed that a relationship of greater affection and dialogue between teacher/student ends up making learning more meaningful.
\end{abstract}

Recebido em: $31 / 12 / 2019$

Aceito em: 08/07/2020 
Keywords: Affection; Teaching and learning; Interpersonal relationship.

\section{INTRODUÇÃO}

O professor desde os tempos remotos é figura de referência para as pessoas. Soares et al. (2019) afirmam que, através dele é possível consolidar uma aprendizagem capaz de ser levada como significativa para o resto da vida. Segundo Freitas, Silva e Santos (2016), a relação interpessoal e a afetividade são fatores fundamentais para o crescimento e desenvolvimento de um ser humano.

Nesse intuito, Oliveira Neto, Santana e Schuvartz (2018) ressaltam que dar margem para o afeto na formação de professores é desarticular um movimento de isolamento, indiferença e fragilidade que ronda o fazer docente, aproximando não só professores e alunos, mas todo o corpo da escola. Pois como aborda Souza (2012, p. 436):

no interior das escolas, as relações afetivas são ambíguas, pois ao mesmo tempo em que os professores demonstram conhecer os estudantes, suas histórias, suas famílias, que parecem dedicar-se a eles, não mostram querer aproximar-se muito afetivamente.

Para tanto, sabe-se que há diferentes conceitos para definir afetividade. Sendo que neste estudo busca-se entender sobre a afetividade e a relação professor/aluno, com base no posicionamento de Wallon, Rabaça e Trindade (1979), onde relatam a respeito da importância da afetividade para o desenvolvimento do ser humano. Para os autores, ela tem papel essencial no processo de desenvolvimento da personalidade, descrevendo que duas funções básicas constituem a personalidade: a afetividade e a inteligência. A afetividade está relacionada às sensibilidades internas e se direciona ao mundo social e para a construção da pessoa. Já a inteligência, diz respeito às sensibilidades externas, tem foco para o mundo físico, para a elaboração do objeto. Assim, as relações que dizem respeito ao sujeito e objeto da aprendizagem e a afetividade, se fazem presentes na mediação que incentiva a empatia e a curiosidade, possibilitando ao educando avançar em suas hipóteses no processo de desenvolvimento e aprendizagem (FERREIRA; OLIVEIRA; ALVES, 2019).

Nesse sentido, razão e emoção não se dissociam, visto que uma necessita da outra. Diferentes estudos (ANJOS, 2013; TAVARES et al., 2019) têm discutido que pensamento e sentimento integram-se, onde entende-se que a aprendizagem é construída 
no social, através de elementos culturais, como cita Luria (1979 apud ANJOS, 2013) que o conhecimento e as habilidades do homem se adquirem por meio da apropriação de diferentes experiências aglomeradas no processo de sua história social transmitindoas para seu processo de ensino-aprendizagem.

Para Tavares et al. (2019) é essencial que as escolas determinem estratégias educacionais que permitam além do desempenho cognitivo, no qual se enfatiza o desenvolvimento das emoções e sentimentos de forma a tornar a aprendizagem mais prazerosa e consolidada. $\mathrm{O}$ educando que apresenta uma relação afetiva-emocional com o seu professor tende a apresentar motivação para aprender, como também apresenta melhores níveis de aprendizagem e de autoestima, o que consequentemente acaba refletindo em um melhor desempenho educacional (BRAIT et al., 2010).

Boa parte da vida do educando é na escola, estudando e tendo uma demasiada convivência com diferentes professores ao longo dessa trajetória. Em suma, vê-se como os alunos tratam a afinidade com os seus professores, podendo destacar entre elas: a ligação com os conteúdos abordados, identificação com a feição e expressividade do professor, com a abertura para diálogos paralelos, entre outras características que fazem com que o aluno se sinta confortável e seguro para relacionar-se com este professor (BARBOSA; CAMPOS; VALENTIM, 2011). Diante do exposto, o objetivo deste trabalho foi verificar a compreensão de professores e alunos sobre a afetividade e a relação desta com o processo de ensino-aprendizagem.

\section{METODOLOGIA}

Este estudo apresenta abordagem qualitativa exploratória em seu desenvolvimento e descritiva na análise dos seus resultados. Com base em Gerhardt e Silveira (2009), a pesquisa qualitativa exploratória é importante para ter maior proximidade com o problema, a fim de construir hipóteses para tentar explicar o porquê de algo estar acontecendo analisando aspectos de forma mais aprofundada, centrada em compreender e explicar os processos das relações sociais.

Inicialmente foi realizado o contato com a escola, a qual foi selecionada por conveniência, a fim de apresentar o projeto de pesquisa a direção e a todos os professores que lecionam no $9^{\circ}$ ano do ensino fundamental. Dos dez professores, quatro se recusaram a responder o questionário, justificando que não teriam tempo disponível 
para respondê-lo. Dentre os que responderam, obteve-se as seguintes informações sobre os sujeitos do estudo: foram seis professoras, todas do sexo feminino, com média de idade de 48,5 anos.

$\mathrm{Na}$ sequência, em um contato posterior, o projeto foi apresentado para as duas turmas do $9^{\circ}$ ano do ensino fundamental da escola, sendo o total de participantes de 40 estudantes, 23 do sexo feminino e 17 do sexo masculino, tendo como média de idade 15 anos e média de tempo de estudo na escola 05 anos.

Para a coleta de dados, foi realizado um contato com as professoras de forma individual para apresentar a proposta da pesquisa e os instrumentos que seriam utilizados. Assim, as que aceitaram participar da pesquisa assinaram o termo de consentimento livre e esclarecido (TCLE) e responderam ao questionário com questões abertas adaptadas do estudo de Dias (2013), sobre a afetividade no processo de ensinoaprendizagem (Quadro 01). A intenção desta primeira coleta foi tentar esclarecer a relação interpessoal entre professor/aluno.

Quadro 01: Questões adaptadas de Dias (2013)

\begin{tabular}{l}
\hline 1. Para você, o que é afetividade? \\
\hline $\begin{array}{l}\text { 2. Para você, é importante existir afetividade entre professor e alunos? Por quê? } \\
\text { forma positiva e outro de forma negativa e descreva como foi o seu relacionamento } \\
\text { com eles: }\end{array}$
\end{tabular}

Fonte: as autoras.

Com relação aos alunos, após a entrega do TCLE e Termo de assentimento assinados, os alunos que tiveram interesse responderam questões sobre a idade, tempo que estudam na escola e sobre "qual disciplina mais gostavam e o porquê". Ainda, foi realizado um grupo focal com cada turma guiado por um roteiro estruturado (Quadro 02) com questões sobre a relação interpessoal professor/aluno e a afetividade no processo de ensino-aprendizagem.

Quadro 02: Roteiro do Grupo Focal

1. Qual disciplina que vocês mais gostam? Descreva as características do professor dessa disciplina.

2. Você acredita que a relação do professor com a turma interfira no fato de você gostar dessa disciplina? De que maneira?

3. Vocês acreditam que a relação do professor com a turma interfere na aprendizagem? Por quê? 


\begin{tabular}{|l|}
\hline 4. Para vocês o que é afetividade? \\
\hline 5. Vocês acreditam que é importante existir afetividade entre professores e alunos? \\
\hline $\begin{array}{l}\text { 6. Durante esse ano qual o professor que demonstrou maior afetividade? Qual a } \\
\text { disciplina que ele ministra? }\end{array}$ \\
\hline 7. Em qual professor vocês dariam um abraço? \\
\hline
\end{tabular}

Fonte: as autoras.

O intuito do grupo focal foi identificar a relação dos alunos com seus professores e com quais professores, de quais disciplinas, a relação era mais próxima. Foi explicado aos alunos que as conversas seriam guiadas por perguntas, e o conteúdo dos diálogos seria gravado em aparelho smartphone da pesquisadora, para posterior transcrição e análise de conteúdo deste material.

Após a coleta dos dados, realizou-se a organização e análise dos questionários dos professores e alunos. Os dados dos grupos focais foram transcritos e armazenados em um documento de texto, tendo sua digitação conferida para evitar possíveis erros de interpretação. Quanto à interpretação e apresentação dos dados, as questões fechadas foram apresentadas em forma de frequência descritiva. Para as questões abertas, utilizou-se a análise de conteúdo de Bardin (2011), que segue três etapas essenciais: a pré-análise, a exploração do material e tratamento dos resultados. Para melhor apresentação da frequência de palavras que surgiram com a categorização, as pesquisadoras utilizaram da criação de nuvens de palavras, elaboradas através do criador WordArt online (wordart.com).

\section{RESULTADOS E DISCUSSÃO}

\subsection{A afetividade e a relação professor/aluno na visão dos professores}

A visão dos professores sobre o entendimento de afetividade foi organizada em uma nuvem de palavras com base na análise de conteúdo das expressões que mais se repetiram entre as professoras, como ilustra a Figura 01. 
Figura 01:

palavras dos

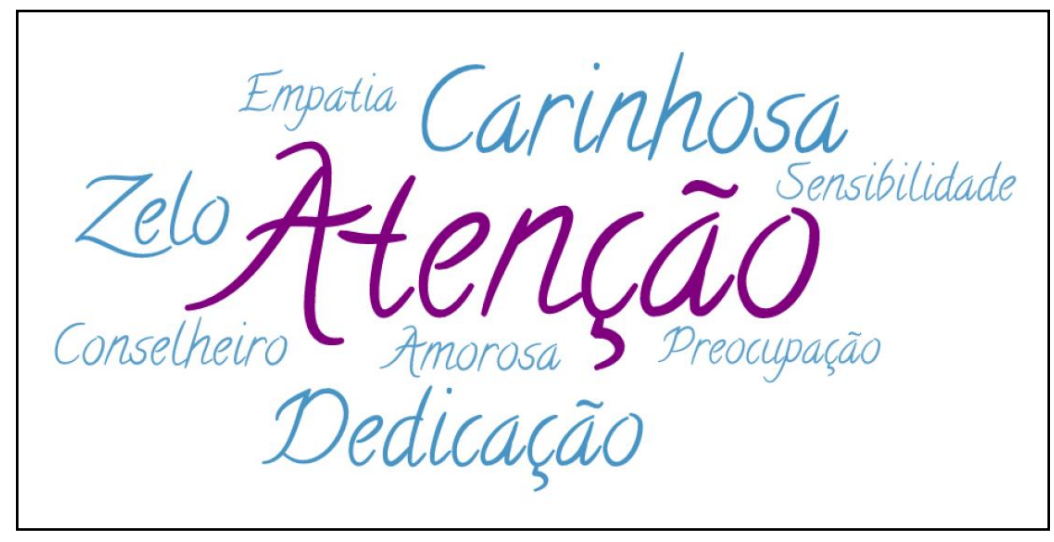

Fonte: As autoras.
Nuvem de professores

Ao analisar-se a nuvem de palavras com as respostas das professoras, observa-se como destaque a palavra atenção, seguida de carinhosa e dedicação. Percebe-se que ao refletir sobre afetividade, fazendo uma relação entre as respostas das professoras de modo geral, a afetividade apresenta-se como forma de cuidar e aconselhar, reparando no comportamento, como fala uma das professoras:

"Afetividade é dar atenção necessária ao aluno, estar atento ao seu comportamento, muitas vezes ser conselheiro do aluno."

Corroborando com os achados, o estudo de Ribeiro e Jutras (2006), aborda que a afetividade pode (ser entendida como um sentimento, uma condição e um comportamento que passam a ser convertidas em diferentes expressões humanas, como: amor, ternura, proteção, cuidado, respeito, aceitação, amizade e afeição entre as pessoas.

Na sequência, os professores foram questionados sobre a importância de existir a afetividade entre professor/aluno Todos os participantes responderam que é importante, como exemplificam as falas abaixo: "Sim. Porque o aluno precisa de atenção para sentir-se bem em sala de
aula"

"Sim. O professor tem que ser afetivo com o aluno mas ao mesmo tempo exigir do aluno o cumprimento das tarefas propostas".

Percebe-se nas frases que a relação conjunta entre professor/aluno é tão importante quanto o conteúdo a ser trabalhado, deve-se entender a realidade do educando destacando também, que o afeto é importante para manter a afeição dos 
mesmos na disciplina. Para Cabral, Carvalho e Ramos (2004), a relação professor/aluno deve buscar um constante equilíbrio entre emoção e razão e para que isso aconteça de forma eficaz, se faz necessário que o diálogo esteja sempre presente nessa relação. Ribeiro (2010) afirma que o relacionamento entre professor/aluno tende a contribuir para a melhoria de comportamentos positivos em relação ao conteúdo das disciplinas escolares e aos professores que as ministram.

Foi solicitado às professoras que comentassem sobre o comportamento de dois alunos que marcaram na sua trajetória durante o ano letivo, onde obteve-se como respostas adjetivos como: amável, interessado, obediente, referindo-se aos alunos de forma positiva, como descreve as falas das professoras a seguir:

"Aluna participativa e obediente, responsável, ajuda a professora durante as aulas além de ajudar e se relacionar bem com os colegas".

[...] "mesmo apresentando dificuldades o aluno era dedicado e estudioso e participativo em sala de aula".

"Aluno interessado, obediente, respeitoso, amável".

Como contraponto surgiram adjetivos como indisciplinados, desobediente e desinteressado para referir-se aos alunos de forma negativa. Como descrevem os trechos abaixo:

\section{"[...] desrespeitoso, desinteressado, desobediente, aluno brincalhão"}

"Aluno rebelde que não aceita e não cumpre regras."

Diante dessas falas percebe-se que o professor leva em consideração a forma que o aluno reflete sua aprendizagem, destacando aspectos de personalidade do aluno juntamente com o relacionamento dele em sala de aula. Nesse sentido, Freitas (1998) relata que, às vezes pelo professor seguir um modelo tradicional de ensino o aluno acaba por sentir-se em uma aula hierarquizada, na qual quebra aquele relacionamento eufônico fazendo com que o aluno adote uma postura rebelde e desinteressada, no qual ele passa a criticar as oposições feitas pelo professor, criando um distanciamento na relação professor/aluno, causando um déficit de aprendizagem tanto para ele quanto para os demais alunos. Em momentos como este, o professor deve assumir a postura de mediador entre razão e emoção, onde deverá repensar a situação, buscando pontos que façam retornar o equilíbrio de ambas as partes, abrindo espaço para discussões com foco 
de resolução dessa falta de interesse por parte do aluno (NORO; ALBUQUERQUE; FERREIRA, 2001).

Ribeiro e Jutras (2006) propõem que é necessário compreender o sentido das práticas dos professores, relativas à afetividade e a maneira como estes reagem quanto aos obstáculos que eles encontram para exercer um método educativo que leve em conta a dimensão afetiva. Diante do que relatam os professores e estudos na área, os tratos pelos quais os professores constituem as relações com seus alunos influenciam no processo educativo. Sabe-se o quanto é imprescindível a relação professor/aluno para um bom relacionamento na escola, e que esse vínculo se torna um fator facilitador em relação ao ensino e a aprendizagem. Assim, buscamos nas próximas linhas identificar a visão dos alunos em relação a afetividade no processo de ensino-aprendizagem.

\subsection{A afetividade e a relação professor/aluno na visão dos alunos}

Por meio do grupo focal com os alunos, pode-se destacar diferentes aspectos do entendimento destes sobre afetividade, o que possibilitou a construção de uma imagem com palavras-chave sobre o conceito que esses alunos têm sobre a afetividade de modo geral. Destacou-se através de uma nuvem de palavras representada na Figura 02, os vocábulos que se sobressaíram nas respostas sobre esta questão.

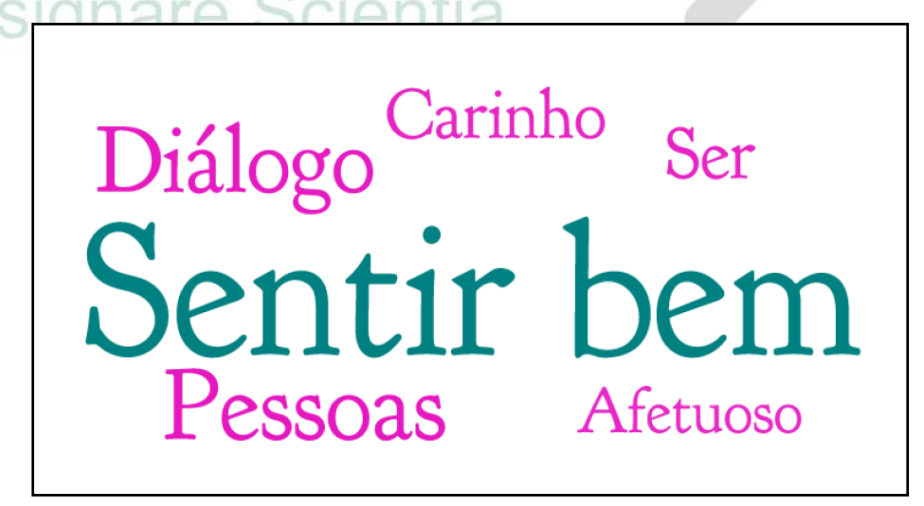

Figura 02: Nuvem de palavras dos alunos Fonte: As autoras.

Ao analisar a nuvem de palavras dos alunos apresenta-se como destaque o termo "Sentir bem" para conceituar a afetividade. Os alunos levam em consideração a forma com que se encontram ou deveriam se encontrar no meio em que estão inseridos, interpretando que, para haver afetividade é necessário que as pessoas tenham diálogo e sejam afetuosas e carinhosas entre si.

Recebido em: $31 / 12 / 2019$

Aceito em: 08/07/2020 
Dias (2013), corrobora com os achados, visto que em seu estudo, as palavras mais repetidas foram "carinho" e "respeito", e trazem à tona o fato de que o ser humano precisa ser atendido nos planos afetivo, cognitivo e motor. Segundo Wallon, Rabaça e Trindade (1979), como também Piletti e Rossato (2011), essa é uma ferramenta valiosa para a educação onde o aluno se beneficia não só do desenvolvimento intelectual, mas da pessoa como um todo porque há nela um crescimento em todos os níveis.

Corroborando com os achados, Sarmento (2010) argumenta que, para o adolescente a construção de sentimentos está ligada a valores atribuídos a si próprio ou através do meio que ele está inserido, estruturados pela cultura e pelas condições históricas. Um ambiente em que há afetividade, carinho e diálogo contribuem de forma mais eficiente para a formação desse adolescente, tornando a vida mais agradável com seus semelhantes.

Com base no questionário respondido pelos alunos, além de perguntas sobre o perfil de cada um, a última das questões pedia para assinalar qual disciplina o aluno mais gostava e justificar de forma descritiva o porquê dessa escolha. Entre as respostas dos quarenta alunos, as disciplinas mais assinaladas foram: História (09), Educação Física (08), Artes (06), Geografia (05) e Português (05), como pode ser observado no Gráfico 01.

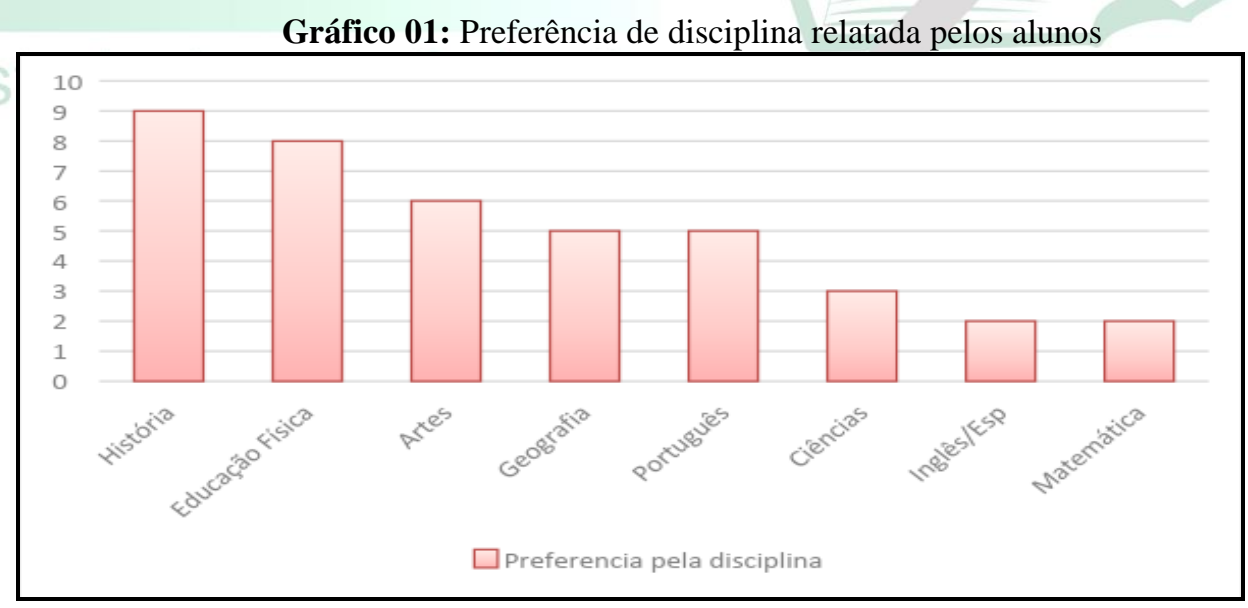

Fonte: as autoras.

Ao analisar o Gráfico 01, observou-se a preferência dos alunos pelas disciplinas de História e Educação Física. Ao serem questionados sobre o porquê de gostar dessas disciplinas, foi realizado um comparativo das respostas, onde os alunos que afirmaram gostar de História alegaram gostar da disciplina por ela ser muito boa, e os alunos que 
citaram a Educação física, justificaram o gosto pela disciplina por gostarem de esportes, como descrevem os trechos a seguir, retirados dos questionários:

\footnotetext{
"Eu gosto porque é uma matéria muito boa, pra saber mais sobre o que aconteceu no Brasil e em outros países, sobre a história da humanidade e etc.".

"Porque história é uma matéria muito boa e a mais fácil."

"Eu gosto de Ed Física porque jogamos futebol e outros esportes."

"Porque eu gosto de esportes."
}

Retomando o grupo focal, os alunos responderam sobre qual disciplina mais gostavam, além de também ter que descrever características do professor dessa disciplina, fazendo uma ligação entre a disciplina e o professor que ministra a mesma. Diante as discussões com ambas as turmas, a disciplina de Geografia que no questionário havia sido assinalada apenas por cinco alunos, foi destacada como a preferida na discussão do grupo focal, seguida da disciplina de Ciências. A preferência dos alunos pelas disciplinas acabou tornando-se divergentes ao comparar os dados do grupo focal com as respostas dos questionários, devido aos alunos fazerem essa ligação entre disciplina e professor. Quanto a disciplina preferida entre as duas turmas, considerando a relação com o professor que a ministra, os alunos enfatizaram em sua maioria gostar do professor de Geografia (que optou por não responder ao questionário), devido ao seu trato com a turma, como argumenta um dos alunos: "Porque ele é parceria, ele conversa com a gente”.

Além disso, o professor mencionado é visto por ambas as turmas por ensinar bem e ter a característica de um bom professor por estar sempre aberto ao diálogo. Já o professor de Ciências é lembrado pelos alunos através das características: "parceria" e "legal". Percebe-se, através da discussão dos alunos no grupo focal, que estes dois professores têm uma boa relação com ambas as turmas.

Segundo Veras e Ferreira (2010), a afetividade tem grande importância no processo de desenvolvimento do indivíduo e na relação com o outro. É por meio do outro que os sujeitos, ao se relacionarem, se delimitam como pessoas no processo de construção permanente. Ainda, é essencial que o professor se envolva e considere "a afetividade como parte do desenvolvimento, buscando a formação integral dos 
estudantes, proporcionando uma vivência positiva da aprendizagem" (VERAS; FERREIRA, 2010, p. 221).

Como ponto negativo, os alunos se referem à disciplina de História como boa, concordando com os dados do gráfico 1, porém possuem dificuldades quanto ao relacionamento com a professora, como pode ser visto pelo comentário de dois alunos a seguir:

\section{“[...] porque a história é boa, mas a professora não ajuda muito.}

"[...] Eu gosto de história, mas a professora me confunde”.

Ainda, entre as questões do grupo focal, foi questionado aos alunos se eles acreditavam que a relação do professor com a turma poderia interferir no fato deles gostarem da disciplina. A resposta foi unânime, com os alunos afirmando que sim, tendo como justificativa que ao gostar mais do professor o aluno passa a prestar mais atenção no conteúdo, tendo como resultado maior interesse na matéria, como citam os alunos nos trechos abaixo:

\section{"Se fosse um professor chato eu não iria gostar", \\ "Um professor mais fechado a gente gosta da matéria, mas não é boa a aula."}

Ao comparar a discussão do grupo focal com as respostas dos questionários, pode-se perceber que os alunos quando questionados apenas pela disciplina que mais gostam citam apenas a preferência particular pela mesma, mas quando a disciplina vem associada à figura do professor que à ministra percebe-se respostas diferentes a dos questionários. Isso corrobora com o estudo de Mello e Rubio (2013) que menciona, que a afetividade é muito importante para que o profissional seja considerado um bom professor e mais ainda, para que o aluno passe a lembrá-lo e admirá-lo.

Nesse sentido, Ribeiro (2010) também afirma, que a relação entre professor/aluno tende a contribuir para melhoria das atitudes positivas, demonstrando que o aluno apresenta maior interesse e compressão nas disciplinas em que o professor perdura um vínculo amigável, onde o mesmo está aberto ao diálogo, demonstra-se afetuoso e interessado nesse aluno. Em estudo do mesmo autor, este percebeu que os professores que seguem essa conduta tendem a influenciar a motivação, a participação e a dedicação aos estudos, diferentes de outros que apesar da disciplina ser interessante 
aos alunos o professor adota uma figura autoritária podem influenciar no desinteresse, na inquietação e na agressividade por parte dos alunos (RIBEIRO; JUTRAS, 2006).

Ao dar continuidade sobre a ideia de relacionamento com o professor, foi perguntado aos alunos se a relação com o professor poderia interferir na aprendizagem deles e em seguida questionava-se o porquê. Novamente a resposta foi afirmativa, sendo alegado pelos alunos que uma boa relação com o professor resulta em um melhor aprendizado e que aula passa a ser mais produtiva, como é citado pelos alunos a seguir:

\section{“[...] dependendo do professor, tipo se a gente gosta do professor a gente vai prestar mais atenção nele."}

"[...] ele tem uma explicação melhor. Tipo, ele explica e trabalha sobre aquilo, e nos escuta melhor."

Para Sarmento (2010), o professor que passa a ter uma sensibilidade com seu aluno utilizando da amizade e do afeto para relacionar-se, passa a amenizar problemas de relacionamento, aumentando o vínculo e a confiança com esse aluno, o que acaba auxiliando o aluno a prestar mais atenção na sua aula resultando em uma aprendizagem mais significativa. Silva (2018) cita que é importante destacar que o processo de ensinoaprendizagem é continuamente um processo de trocas, dado que, ao mesmo tempo em que o aluno está aprendendo ele ensina, e quando o professor está ensinando, também, aprende com o aluno. Sempre levando em consideração que a relação professor/aluno em / sala de aula deve ter limites estabelecidos, disciplina na hora das atividades e respeito para que o ensino-aprendizagem aconteça (PAIVA, 2019).

Os alunos acreditam que é importante existir afetividade entre professor/aluno, pois a partir deste sentimento se dá uma boa convivência no ambiente escolar. Partiu-se então para questão que os fazia refletir sobre qual professor durante o atual ano letivo demonstrou maior afetividade com a turma e qual disciplina ele ministra, obteve-se como resposta novamente Ciências e, surgiu a disciplina de Ensino Religioso como as mais citadas, sendo estas lembradas devido a forma que os professores tratam os alunos, como descrevem as falas a seguir:

\footnotetext{
"O jeito que ela nos trata e tenta nos ensinar mesmo alguns não querendo aprender no caso, mesmo a pessoa não querendo aprender ela busca o aluno pra tentar ensinar, ela ajuda."
}

"A professora [...] te trata como filho cara". 
Percebe-se o quanto os alunos retratam a figura do professor ligados a sentimento de afetividade, principalmente ao se referir a essa professora, a qual os compara com uma "figura materna", fazendo com que esse aluno se sinta acolhido indo em busca dele, demonstrando apostar no seu conhecimento e potencial, podendo dizer que quanto mais proximidade eles apresentam com esse professor, maior será a interação e melhor convivência na aula.

Nesse sentido, Paiva (2019) afirma que a orientação e o estímulo são fundamentais no processo de ensino e do desenvolvimento do aluno, pois o aprendizado ocorre no equilíbrio entre cognição e emoção. Diante do processo de ensinoaprendizagem o diálogo é ferramenta essencial entre professor/aluno, visto que, através dele, possibilita-se uma mediação dos conhecimentos valorizando o respeito e as diferenças. O professor passa a observar e tentar compreender as dificuldades de aprendizagem do aluno para poder executar as atividades proporcionando novos conhecimentos, considerando esse aluno como um sujeito construtor de conhecimento, identidade e, também, da sua cultura (CARVALHO; ROLÓN; MELO, 2018).

Para finalizar, os alunos foram instigados a pensar em qual dos seus professores eles dariam um abraço. Os professores das disciplinas de Geografia e Ensino Religioso foram novamente os mais lembrados pelas duas turmas. Sendo o professor de Geografia citado como o que mais respeita os alunos, por ser compreensivo e ótimo professor; e a professora de Ensino Religioso lembrada por sempre se importar com a turma, mesmo passando por momentos difíceis na vida pessoal. As falas a seguir ilustram estas afirmações:

\section{“[...] ele é lembrado pelo respeito, é compreensivo”. \\ "Ela é uma pessoa muito esforçada" \\ "[...] passou por momentos dificeis, perdeu marido, mas sempre tentando passar o conteúdo, ouvindo os alunos".}

Observando as falas dos alunos podemos considerar que o aluno passa enxergar o professor além da sala de aula a partir do momento que o mesmo o envolve, partilhando momentos e situações pessoais através dessa convivência diária. $\mathrm{O}$ aluno passa a ver esse professor como um exemplo, criando sentimento de respeito e compreensão com o mesmo que antes de tudo é um ser humano. Como é apresentado na reflexão de Chaves, Santos e Bezerra (2018) onde, o professor deve ser pensado na 
presença da sua identidade profissional sendo associada a sua identidade pessoal, tornando-o um ser total com suas concepções, dificuldades e valores.

Ao questionar o cotidiano da sala de aula foi possível encontrar diferentes situações e conflitos entre professor/aluno, tendo como motivos diversos fatores. É oportuno reparar o propósito do professor em encarar esses conflitos entre razão e emoção e tirar disso possibilidades de refletir. É a partir desse ponto que podemos destacar que a afetividade se torna mais que a demonstração de carinho. É em situações adversas que se deve desenvolver o diálogo entre professor/aluno, diante dessa troca, que o professor torna-se figura importante para estimular o interesse e a necessidade de conscientização, percebendo assim, que uma relação de maior afetividade e diálogo entre ambos acaba por tornar a aprendizagem mais significativa para o educando.

\section{CONSIDERAÇÕES FINAIS}

Com base nos resultados e discussões apresentados neste estudo, observa-se que a afetividade se apresenta de forma positiva na relação professor/aluno em sala de aula, tornando o processo de ensino-aprendizado mais significativo a esses alunos, sendo o professor a principal fonte mediadora para esse processo.

Percebeu-se que a relação professor/aluno se desenvolve perante a combinação da afetividade e aprendizagem. O afeto esteve presente de forma relevante na fala dos alunos e professores, através de espaços para elogios, incentivos e demonstração de afeição. Até mesmo a repreensão, quando necessária, apresentou-se de forma direcionada como possibilidade de reflexão e conscientização. Em suma, a afetividade em conjunto com o diálogo, é um dos componentes essenciais para que essa relação seja significativa, refletindo diretamente no processo de ensino-aprendizagem.

Por fim, destaca-se que por se tratar de um estudo com adolescentes, identificou-se que o grupo focal foi mais adequado aos objetivos da pesquisa do que o questionário. Apesar do questionário não exigir muito tempo, e nem muito esforço de escrita, o grupo focal foi mais eficiente. Pois ao longo das questões realizadas pela mediadora, os alunos se sentiram mais à vontade ao diálogo, através das respostas aos questionamentos falavam sobre seus sentimentos relacionados aos professores, acabando por trazer mais significado aos resultados do estudo. 


\section{REFERÊNCIAS}

ALBUQUERQUE, Carlos. Processo ensino-aprendizagem: características o professor eficaz. Millenium, p. 55-71, 2010.

ANJOS, Ricardo Eleutério. O desenvolvimento psíquico na idade de transição e a formação da individualidade para-si: aportes teóricos para a educação escolar de adolescentes. Dissertação (Mestrado em Educação Escolar). Universidade Estadual Paulista. Faculdade de Ciências e Letras. Araraquara-SP, 2013.

BARBOSA, Altemir José Gonçalves; CAMPOS, Renata Araújo; VALENTIM, Tássia Azevedo. A diversidade em sala de aula e a relação professor-aluno. Estudos de psicologia, v. 28, n. 4, p. 453-461, 2011.

BARDIN, Laurence. Análise de conteúdo. São Paulo: Edições 70, 2011.

BRAIT, Lílian Ferreira Rodrigues et al. A relação professor/aluno no processo de ensino e aprendizagem. Itinerarius Reflectionis, v. 6, n. 1, 2010.

CABRAL, Fábia Moreira Squarça; DE CARVALHO, Maria Aparecida Vivan; RAMOS, Rosângela Mancini. Dificuldades no relacionamento professor/aluno: um desafio a superar. Paidéia, v. 14, n. 29, p. 327-335, 2004.

CHAVES, Natalina Bissaro Siqueira; SANTOS, Paula Tauana; BEZERRA, Ada Augusta Celestino. Contribuições da afetividade na sala de aula: relações interpessoais e desenvolvimento da aprendizagem. Encontro Internacional de Formação de Professores e Fórum Permanente de Inovação Educacional, v. 11, n. 1, 2018.

CARVALHO, Elisiane Alves de; ROLÓN, Julio Cesar Cardozo; MELO, Joeuda Sandra Magalhães. Os Vínculos Afetivos na Construção do Ensino Aprendizagem. Id on line Revista Multidisciplinar e de Psicologia, v. 12, n. 39, p. 469-488, 2018.

DIAS, Luzia Inácio. Afetividade no ensino médio: a percepção de professores e alunos. Monografia (Especialização em Coordenação Pedagógica) Universidade de Brasília, Brasília, 2013.

FERREIRA, Beatriz Reis; OLIVEIRA, Michel Amorim de; ALVES, Renata Farche. Psicologia e ensino: análise de contexto escolar na perspectiva de wallon. Revista Educação-UNG-Ser, v. 14, n. 1, p. 91-97, 2019.

FREITAS, Edmary da Silva; DA SILVA, Lidiane Santos; SANTOS, Maria Isabel da Gama. Afetividade enquanto fator de motivação para a aprendizagem da criança. Disponível em: < https://portal.fslf.edu.br/wp content/uploads/2016/12/AFETIVIDADE-ENQUANTO-FATOR.pdf>Acesso em: nov 2019 . 
FREITAS, Lia. A produção da ignorância na escola: uma análise crítica do ensino da língua escrita na sala de aula. São Paulo: Cortez, 1998.

GERHARDT, Tatiana Engel; SILVEIRA, Denise Tolfo. Métodos de pesquisa.

Plageder, 2009.

MELLO, Tágides; RUBIO, Juliana de Alcântara Silveira. A importância da afetividade na relação professor/aluno no processo de ensino/aprendizagem na educação infantil. Revista Eletrônica Saberes da Educação, v. 4, n. 1, p. 1-11, 2013.

NORO, Luiz Roberto Augusto; ALBUQUERQUE, Danielle Frota; FERREIRA, Maria Elisa Machado. O desenvolvimento do processo ensino-aprendizagem: visão do aluno e do professor. Cinquentenário da ABENO, v. 1, n. 1, p. 109-14, 2001.

OLIVEIRA NETO, José Firmino; SANTANA, Aline Neves Vieira; SHUVARTZ, Marilda. A formação de professores (as) em ciências biológicas. Revista Insignare Scientia-RIS, v. 1, n. 1, 2018.

PAIVA, Márcia Maria Soares. A afetividade e o processo ensino-aprendizagem. Trabalho de conclusão de curso. Universidade do Estado do Amazonas. 2019. Disponível em: < http://repositorioinstitucional.uea.edu.br//handle/riuea/1483 >. Acesso em: nov/2019.

PILLETI, Nelson, ROSSATO, Solange Marques. Psicologia da Aprendizagem: da teoria do condicionamento ao construtivismo. São Paulo: Contexto, 2011.

RIBEIRO, Marinalva Lopes; JUTRAS, France. Representações sociais de professores sobre afetividade. Estudos de psicologia, v. 23, n. 1, p. 39-45, 2006.

RIBEIRO, Marinalva Lopes. A afetividade na relação educativa. Estudos de psicologia, v. 27, n. 3, p. 403-412, 2010.

SARMENTO, Nara Regina Goulart. Afetividade e Aprendizagem. Porto Alegre: UFRGS, 2010. Disponível em: https://www.lume.ufrgs.br/bitstream/handle/10183/71877/000880292.pdf? sequence=1. Acesso em: set/2019.

SILVA, Andreza Fernanda da. Implicações na relação professor-aluno: a afetividade no processo de ensino-aprendizagem. 2018.

SOARES, João Francisco Selhorst et al. As habilidades sociais como fatores aliados às práticas do professor. Revista da Universidade Vale do Rio Verde, v. 17, n. 1, 2019.

SOUZA, R. C. C. R. Novos paradigmas: pontes entre o mal-estar e o bem-estar docente. Linhas críticas, n. 36, p. 433-453, 2012.

TAVARES, Maria Eliene Pessôa Assunção et al. Afetividade: fator indispensáel à aprendizagem/Affectiveness: a factor which is indispensable for learning. Brazilian Journal of Development, v. 5, n. 11, p. 25710-25717, 2019.

Recebido em: $31 / 12 / 2019$

Aceito em: 08/07/2020 
Vol. 3, n. 5. Set./Dez.

ISSN: 2595- 4520

VERAS, Renata da, FERREIRA, Sandra Patrícia Ataíde. A afetividade na relação professor e aluno e suas implicações na aprendizagem, em contexto universitário.

Educar em revista, Curitiba, n. 38, set./dez. 2010.

WALLON, Henri; RABAÇA, Ana Maria; TRINDADE, Calado. Psicologia e educação da criança. 1979. 